\title{
Maintaining infliximab induced clinical remission with azathioprine and 5-aminosalicylates in acute severe steroid-refractory ulcerative colitis has lower cost and high efficacy (MIRACLE): a multicenter study
}

\author{
Ramit Mahajan ${ }^{1 *}$, Arshdeep Singh ${ }^{1 *}$, Saurabh Kedia ${ }^{2}$, Kirandeep Kaur ${ }^{3}$, Vandana Midha ${ }^{4}$, Pabitra Sahu ${ }^{2}$, Varun Mehta ${ }^{1}$, \\ Dharmatma Singh ${ }^{5}$, Namita Bansal ${ }^{6}$, Khushdeep Dharni ${ }^{7}$, Sandeep Kaushal ${ }^{3}$, Vineet Ahuja ${ }^{2}$, Ajit Sood ${ }^{1}$ \\ ${ }^{1}$ Department of Gastroenterology, Dayanand Medical College, Ludhiana; ${ }^{2}$ Department of Gastroenterology and Human Nutrition, All India \\ Institute of Medical Sciences, New Delhi; Departments of ${ }^{3}$ Pharmacology and ${ }^{4}$ Internal Medicine, ${ }^{5}$ CRC, Research and Development Centre, \\ and ${ }^{6}$ Research and Development Centre, Dayanand Medical College, Ludhiana, ${ }^{7}$ School of Business Studies, Punjab Agricultural University, \\ Ludhiana, India
}

Background/Aims: Infliximab (IFX) has been used to induce and maintain remission in patients with severe steroid-refractory ulcerative colitis (UC). Long-term use of biologics in developing countries is limited by high cost and frequent side effects. An optimal maintenance strategy in these patients needs to be established. Methods: A retrospective analysis of maintenance of clinical remission with combination of azathioprine (AZA) and 5-aminosalicylates (5-ASA) in patients with severe steroidrefractory UC where IFX $(5 \mathrm{mg} / \mathrm{kg}$ intravenously at weeks $0,2,6)$ had been used only as an induction therapy was done at 2 centers in India. Primary outcome was the proportion of patients maintaining corticosteroid-free sustained clinical remission (SCR) at the end of study period. Rates of relapse and cost of therapy were also analyzed. Results: Of the 137 patients who received rescue IFX induction therapy, 77 (56.2\%) achieved clinical remission (mean age $34.81 \pm 13.32$ years, 68.83\% males, median follow-up 4 years, range 3 months to 6 years) and were included. Cumulative corticosteroid-free SCR was maintained in $68 \%, 59 \%, 42 \%$, and $35 \%$ patients at 1, 2, 4, and 6 years respectively. Sixty-seven relapses were observed in 33 patients. Majority of the relapses $(45 / 67,67.16 \%)$ occurred within first 2 years of follow-up. Two relapses were managed with re-induction with IFX, one required colectomy, whereas all other responded to repeat course(s) of corticosteroids. Annual per capita maintenance therapy with 5-ASA and AZA was cheaper by US\$ 4,526 compared to maintaining remission with IFX. Conclusions: Clinical remission achieved with IFX induction therapy in severe steroid-refractory UC can be sustained over long time with a combination of AZA and 5-ASA. (Intest Res 2022;20:64-71)

Key Words: Colitis, ulcerative; Maintenance; Infliximab; Azathioprine; Mesalamine

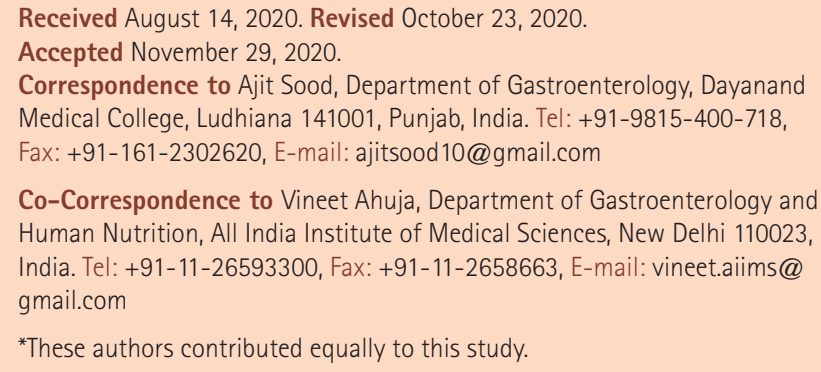

*These authors contributed equally to this study.

\section{INTRODUCTION}

Ulcerative colitis (UC) is a chronic inflammatory disease of the colon with a relapsing remitting course. ${ }^{1}$ Acute severe exacerbations of the disease develop in $15 \%$ to $20 \%$ of the patients, requiring hospitalization and treatment with intravenous (IV) corticosteroids. ${ }^{2}$ Though corticosteroids are effective 
in a majority of patients with severe UC, they are not a panpharmacon. Up to one-third of patients with acute severe UC may fail to respond to therapy with IV corticosteroids and hence require rescue therapy with IV cyclosporin A (CsA)/infliximab (IFX) or colectomy. ${ }^{3-7}$ In patients where IFX is used as rescue therapy, continuation of an 8 weekly dosing schedule has been recommended for maintenance of remission. However, up to $30 \%$ of patients may not be able to continue IFX in the long run due to adverse events or a secondary loss of response. ${ }^{8,9}$ Furthermore, the continued use of biologics for maintenance of remission is not feasible in developing countries where the health insurance coverage is minimal, placing significant economic burden on the patients. To sustain clinical remission in these patients, alternative maintenance therapies need to be studied. We present a multicenter experience of use of combination therapy with azathioprine (AZA) and 5-aminosalicylates (5-ASA) for maintenance of clinical remission in patients with acute severe steroid-refractory UC who achieved clinical remission with IFX induction regimen and IFX was stopped thereafter.

\section{METHODS}

\section{Setting}

This was a retrospective analysis of database from 2 tertiary care centers in north India; Dayanand Medical College and Hospital, Ludhiana and All India Institute of Medical Sciences, New Delhi. Patients with acute severe steroid-refractory UC who received IFX as a rescue induction therapy and subsequently maintained on 5-ASA and AZA between August 2005 and December 2017 were enrolled. The study was approved by Institutional Ethics Committee (IEC Nos. DMCH/R\&D/2020/23 and IECPG-599/ 24.10.19) of both the institutions and performed in accordance with the principles of the Declaration of Helsinki. Written informed consent was obtained.

\section{Study Population}

Adult ( $\geq 18$ years) patients with acute severe UC (defined as 6 or more stools with blood and 1 or more of the following hemoglobin $<10.5 \mathrm{~g} / \mathrm{dL}$, erythrocyte sedimentation rate [ESR] $>30 \mathrm{~mm} / \mathrm{hr}$, fever $>37.8^{\circ} \mathrm{C}$, or tachycardia $>90 / \mathrm{min}$; the Truelove Witts criteria) refractory to IV hydrocortisone (300-400 $\mathrm{mg} /$ day administered in 3 divided doses, used for 5-7 days) were offered rescue therapy with either IFX (originator, induction protocol: $5 \mathrm{mg} / \mathrm{kg}$ at weeks 0,2 , and 6$) / \mathrm{CsA}(2 \mathrm{mg} / \mathrm{kg}$ infusion for 5 days, followed by oral CsA acting as bridge to thiopu- rines); or colectomy. The current study is a retrospective analysis of treatment outcomes of the patients who opted for IFX as a rescue therapy and achieved clinical remission. Clinical remission was defined as partial Mayo score $\leq 1$ at week $10 .^{10}$

AZA was introduced/continued in all patients, whether AZA naïve or experienced, at the time of first dose of IFX induction regime. The patients who achieved clinical remission were followed for maintenance of corticosteroid-free sustained clinical remission (SCR) with combination therapy of AZA and 5-ASA. Corticosteroid-free SCR was defined as partial Mayo score $\leq 1$ with absence of diarrhea and blood in stools and without need for new courses of corticosteroids or any other systemic drug (CsA, biologics, or investigational drugs). ${ }^{11}$ 5-ASA was used in a dose of 3.6-4.8 g/day and the dose of AZA was maintained at $1.5-2 \mathrm{mg} / \mathrm{kg} /$ day. All the patients were followed at an interval of 8-12 weeks, or earlier in case of worsening of symptoms. Disease activity (partial Mayo score) and concomitant pharmacotherapy were recorded for each visit. Patients with adverse events necessitating drug withdrawal were excluded.

Relapse was defined as partial Mayo score $\geq 3$. $^{12}$ In case of relapse, stool examination for infections including Clostridioides difficile; and IgM serology and histology for cytomegalovirus were performed. The management protocols for each relapse, including use of corticosteroids, biologics (IFX), CsA or surgery, were noted.

Patients with failure to achieve clinical remission with IFX induction therapy, incomplete induction protocol, active or latent tuberculosis, hepatitis B, hepatitis $\mathrm{C}$, human immunodeficiency virus (HIV), pathogens on stool culture, contraindication to IFX or AZA according to labelling recommendations, previous use of multiple biologics, Crohn's colitis/inflammatory bowel disease (IBD)-unclassified, pregnancy or lactation, and patients with missing data were excluded.

\section{Cost-Benefit Analysis}

Cost-benefit analysis of AZA plus 5-ASA was done in comparison to IFX maintenance. The cost of drug used in analysis was based on maximum retail price of the drugs. Annual expenditure (including the cost involved in treatment of relapses, hospitalization, rescue therapy and surgery) were estimated and compared between the 2 approaches.

\section{Clinical Outcomes}

The primary outcome was maintenance of corticosteroid-free SCR during the follow-up. Secondary outcomes included as- 
sessment of rates of relapses and their management and costbenefit analysis.

\section{Statistical Analysis}

Descriptive statistics were provided with mean and standard deviation, median and interquartile range for continuous variables and frequency and percentage for categorical variables. Log-rank test was used to investigate the factors affecting relapse after cessation of IFX therapy. Using the standard $\alpha=0.05$ cutoff, $P<0.05$ was considered statistically significant. Cumulative relapse-free survival (corticosteroid-free SCR) was calculated using Kaplan-Meier survival analysis. All statistical analyses were performed using Stata 12 (StataCorp. 2011. Stata Statistical Software: Release 12; StataCorp LP, College Station, TX, USA).

\section{RESULTS}

A total of 137 patients with acute severe UC were treated with IFX for inducing remission during the study period. Twentythree patients (17.1\%) did not respond to IFX and underwent colectomy, 5 (3.7\%) had adverse events (tuberculosis: $\mathrm{n}=3$; congestive heart failure: $\mathrm{n}=2)$ and $32(23.4 \%)$ either had adverse events/poor compliance with AZA or were lost to follow-up. The 77 patients (56.2\%) who achieved clinical remission were followed (median, follow up 4 years; range, 3 months-6 years) for disease course (Fig. 1). These patients were maintained on 5-ASA (median, $4.8 \mathrm{~g} /$ day; range, 3.6-4.8 $\mathrm{g} /$ day) and AZA (median, $100 \mathrm{mg} /$ day; range, $50-150 \mathrm{mg} /$ day). IFX was stopped after the induction regimen. The baseline characteristics of these patients are listed in Table 1.

\section{Corticosteroid-Free SCR}

Seventy-seven patients (mean age, $34.81 \pm 13.32$ years; $68.83 \%$ of males, $n=53$ ) with acute severe steroid-refractory UC achieving clinical remission with IFX were followed up. The mean duration of corticosteroid-free SCR with 5-ASA and AZA was $2.70 \pm 2.17$ years (median, 1.5 years). The cumulative corticosteroid-free SCR at the end of follow-up (6 years) was $35 \%$. The cumulative relapse-free survivals at 1,2 , and 4 years were $68 \%, 59 \%$, and $42 \%$ respectively (Fig. 2).

\section{Rates and Patterns of Relapse}

Thirty-three patients (42.85\%) suffered a total of 67 relapses over the entire follow-up period. Twelve (36.36\%) of these 33 patients suffered $>1$ relapses. Majority of the patients $(n=27$,

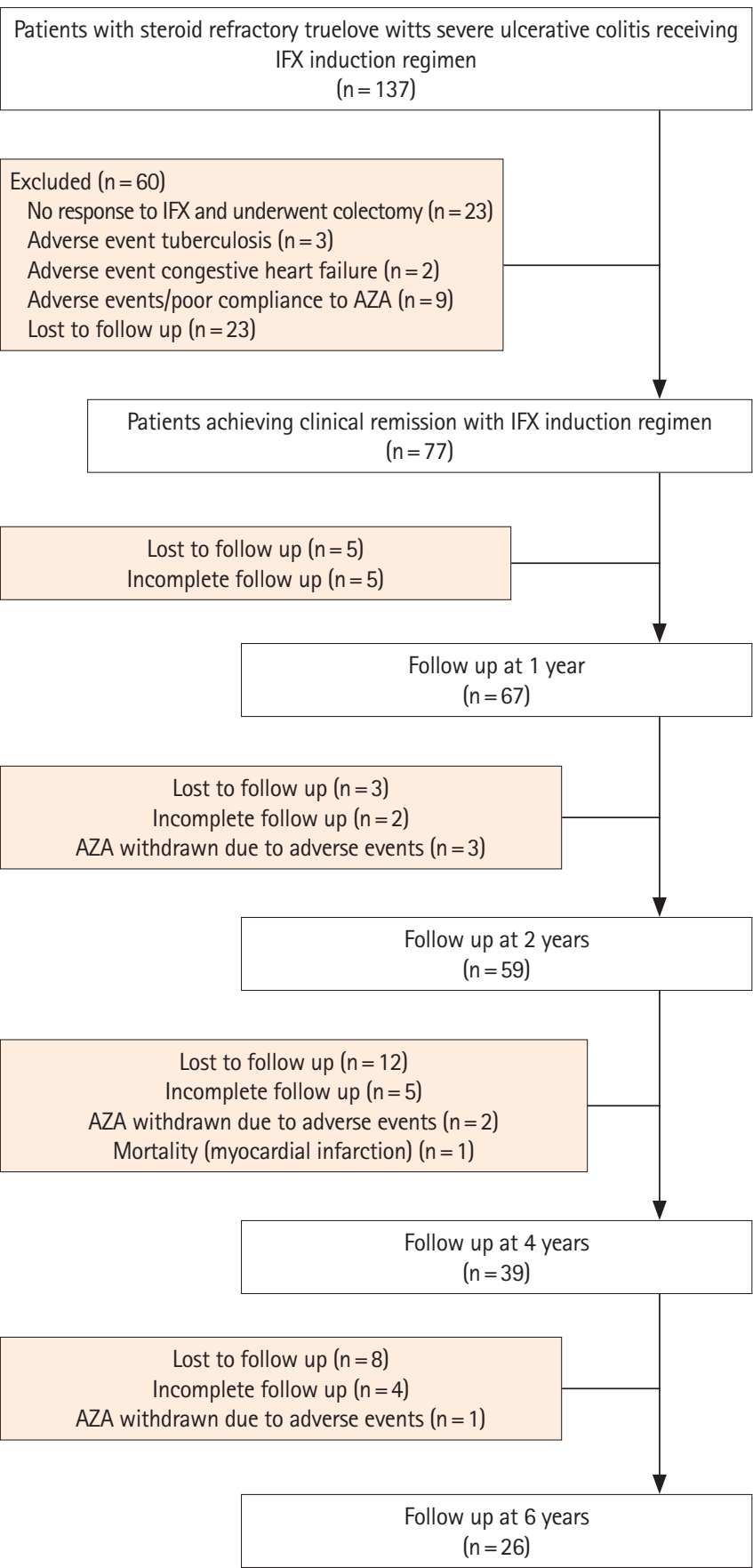

Fig. 1. Flowchart of the patients in the current study. IFX, infliximab; AZA, azathioprine.

$81.81 \%$ ) relapsed within first 2 years of follow-up. Of the total 67 relapses, 64 (95.52\%) were managed successfully with repeat courses of corticosteroids whereas 2 needed re-induction with IFX and 1 needed colectomy (Table 2). The factors that influenced corticosteroid-free SCR were evaluated. No significant effects of age, sex, disease duration, disease severity (Mayo score), disease extent, previous exposure to AZA and 
Table 1. Baseline Characteristics of the Patients

\begin{tabular}{lc}
\hline Characteristics & Value $(\mathrm{n}=77)$ \\
\hline Age $(\mathrm{yr})$ & $34.81 \pm 13.32$ \\
Sex & \\
$\quad$ Male & $53(68.83)$ \\
Female & $24(31.16)$ \\
Disease extent & \\
E2 & $47(61.03)$ \\
E3 & $30(38.96)$ \\
Duration of disease (yr) & $1.84(0.25-17.00)$ \\
Total Mayo score (before IFX induction regimen) & $8.87 \pm 1.14$ \\
CRP (mg/L) & $51.26 \pm 64.14$ \\
ESR (mm/hr) & $52.90 \pm 20.18$ \\
Albumin (g/dL) & $3.26 \pm 0.85$ \\
Hemoglobin (g/dL) & $9.98 \pm 1.94$ \\
Previous AZA use & \\
Experienced & $27(35.06)$ \\
Naïve & $50(64.93)$ \\
\hline
\end{tabular}

Values are presented as mean \pm standard deviation, number (\%), or median (range).

E2, left-sided colitis; E3, pancolitis, IFX, infliximab; CRP, C-reactive protein; $E S R$, erythrocyte sedimentation rate; $A Z A$, azathioprine.

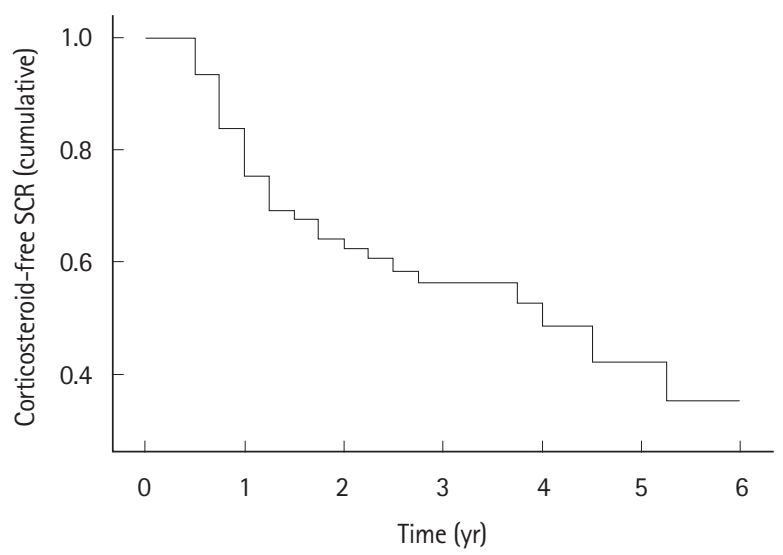

Fig. 2. Kaplan-Meier cumulative survival curve for corticosteroidfree sustained clinical remission (SCR).

inflammatory markers (ESR, C-reactive protein, and albumin) were observed (Table 3 ).

\section{Adverse Events}

Eight patients had adverse events due to AZA (hepatotoxicity: $\mathrm{n}=4$, pancreatitis: $\mathrm{n}=2$, and leukopenia: $\mathrm{n}=2$ ). Six of these discontinued AZA (hepatotoxicity: $\mathrm{n}=2$, pancreatitis: $\mathrm{n}=2$, and leukopenia: $\mathrm{n}=2$ ) and were excluded from the analysis. Of
Table 2. Patterns of Disease Relapse and Treatment

\begin{tabular}{lccc}
\hline Year & $\begin{array}{c}\text { No. of patients } \\
\text { with single } \\
\text { relapse }\end{array}$ & $\begin{array}{c}\text { No. of patients } \\
\text { with } \\
>1 \text { relapse }\end{array}$ & $\begin{array}{c}\text { No. of } \\
\text { relapses }\end{array}$ \\
\hline 1 & $14^{\mathrm{a}}$ & $8^{\mathrm{a}}$ & 31 \\
2 & $4^{\mathrm{b}}+4^{\mathrm{a}}$ & $2^{\mathrm{b}}+1^{\mathrm{a}}$ & 14 \\
3 & $2^{\mathrm{b}}+1^{\mathrm{a}}$ & $2^{\mathrm{b}}+1^{\mathrm{a}}$ & 9 \\
4 & $3^{\mathrm{b}}$ & $2^{\mathrm{a}}$ & 7 \\
5 & $2^{\mathrm{a}}$ & $1^{\mathrm{b}}$ & 4 \\
6 & $1^{\mathrm{b}}$ & - & 2 \\
Total & & & 67 \\
Treatment & & & $\begin{array}{c}\text { Corticosteroids: 64 } \\
\text { Infliximab: 2 (1 } \\
\text { patient each in } \\
\end{array}$ \\
& & & $\begin{array}{c}\text { year 1 and 2) } \\
\text { Colectomy: } 1 \text { (year 3) }\end{array}$ \\
\hline
\end{tabular}

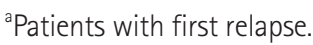

${ }^{b}$ Patients who also relapsed in previous years.

Table 3. Factors Influencing the Maintenance of CorticosteroidFree Sustained Clinical Remission

\begin{tabular}{lccc}
\hline Parameter & Odds ratio & $95 \% \mathrm{Cl}$ & $P$-value \\
\hline Age & 1.00 & $0.97-1.03$ & 0.74 \\
Male sex & 0.60 & $0.23-1.60$ & 0.31 \\
Disease duration & 1.01 & $0.92-1.11$ & 0.71 \\
Disease extent E2 & 0.07 & $0.00-1.48$ & 0.09 \\
AZA naïve & 0.68 & $0.24-1.90$ & 0.47 \\
Mayo score & 1.13 & $0.74-1.71$ & 0.56 \\
Hemoglobin $(\mathrm{g} / \mathrm{dL})$ & 1.01 & $0.77-1.32$ & 0.92 \\
ESR (mm/hr) & 1.00 & $0.97-1.02$ & 0.93 \\
Albumin (g/L) & 0.79 & $0.45-1.40$ & 0.43 \\
CRP (mg/L) & 0.99 & $0.99-1.01$ & 0.47 \\
\hline
\end{tabular}

$\mathrm{Cl}$, confidence interval; E2, left-sided colitis; $\mathrm{AZA}$, azathioprine; ESR, erythrocyte sedimentation rate; CRP, C-reactive protein.

these 6 patients, 2 underwent fecal microbiota transplantation, 1 was started on methotrexate and 3 patients shifted to complementary and alternative medicine. Two patients who had mildly elevated liver enzymes tolerated split dose AZA (AZA administered in 2 divided doses) and continued on therapy. None of the 2 patients who required re-induction with IFX had infusion reaction on re-induction infusions. Two patients died during the study period; 1due to surgical complications after colectomy and another due to myocardial infarction, unrelated to UC. 
Table 4. Cost-Benefit Analysis (Annual) $(n=77)$

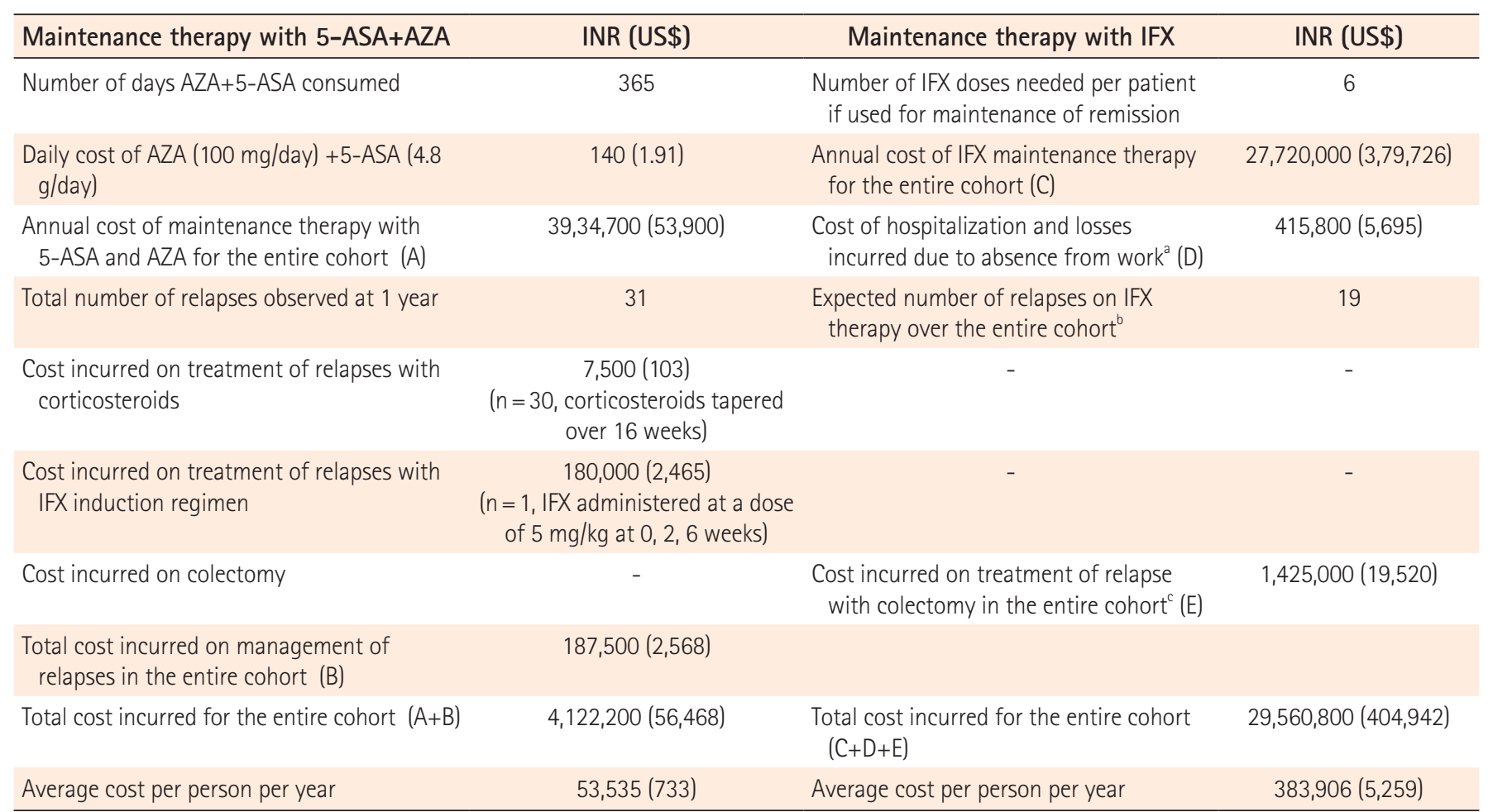

All values are approximate 1US\$ (INR 73). Annual cost difference per patient: INR 330,371 (US\$ 4,526). Cohort size (n) =77; Cost of IFX originator: INR 20,000/100 mg; Cost of AZA 100 mg: INR 20; Cost of oral 5-ASA $4.8 \mathrm{~g}$ : INR 120; Cost of colectomy in a tertiary care center: INR 75,000; Costs calculated for average body weight of $60 \mathrm{~kg}$.

${ }^{a}$ For a single day care admission approximate cost of hospitalization: INR 500 for a tertiary care hospital (data derived from World Health Organization report on Estimates of Unit Costs for Patient Services for India; available at https://www.who.int/choice/country/ind/cost/en/, accessed on 0ctober 18, 2020) and approximate loss of income due to absence from work: INR 370 (data derived from per capita income in India for 2018-2019; available at http://mospi.govin, accessed on October 18, 2020).

${ }^{b}$ Calculated considering average relapse rates of $25 \%$ and $30 \%$ at 1 year and 2 years respectively. $8,17,23,24$

'Biologics other than anti-tumor necrosis factor agents are not available in India, so the only therapeutic option for patient relapsing on IFX is colectomy. 5-ASA, 5-aminosalicylic acid; AZA, azathioprine; IFX, infliximab.

\section{Cost-Benefit Analysis}

Cost-benefit analysis was performed by comparing the therapeutic benefits (including the proportion of patients maintaining corticosteroid-free SCR and frequency of relapses) and costs incurred on the therapy. Comparisons were made for IFX used as maintenance therapy versus IFX used only for inducing remission and maintaining with 5-ASA and AZA. The relapse rates with IFX maintenance were derived from the existing literature reporting long-term efficacy of IFX. Annual costs were calculated based on absolute compliance to therapy, the number of relapses observed/expected and costs incurred on management of relapses. Maintenance therapy per capita per annum was cheaper by US\$ 4,526 with 5-ASA and AZA as compared to maintaining remission with IFX (Table 4).

\section{DISCUSSION}

In acute severe UC, corticosteroids are the initially recommended drugs. However, a subset of patients is refractory to corticosteroids and need rescue therapy with IFX. Both ECCO (European Crohn's and Colitis Organisation) and ACG (American College of Gastroenterology) guidelines recommend that remission achieved with IFX should be maintained with the same, either alone or in combination with thiopurines. ${ }^{13,14}$ However, maintenance of remission with IFX every 8 weeks is difficult in real world settings in resource-limited countries like India. Apart from cost, there are safety concerns as the use of IFX in areas with high prevalence of tuberculosis carries a risk of reactivation, even in the absence of latent tuberculosis. ${ }^{15}$ The present study highlights the role of combination therapy with AZA and 5-ASA as effective maintenance therapy for pa- 
tients with severe steroid-refractory UC who required IFX as a rescue induction therapy. Cumulative corticosteroid-free SCR was achieved in $35 \%$ of patients at 6 years. A total of 67 relapses were observed in 33 patients. Majority of the relapses (45/67, 67.16\%) occurred within first 2 years of follow-up. Two relapses were managed with re-induction with IFX, 1 required colectomy, whereas all other responded to repeat course(s) of corticosteroids.

Thiopurines are immunosuppressive agents with proven clinical efficacy and long-term safety in patients with IBD. ${ }^{16,17}$ However, the primary obstacle to their use in an acute flare is their delayed onset of action. Therefore, IFX was used in the current study only to induce remission and rapidly decrease tumor necrosis factor (TNF)- $\alpha$ secretion; thereby normalizing dysregulated immunity, reducing intestinal inflammation, and restoring mucosal immune homeostasis. ${ }^{18-21}$ The clinical remission achieved by IFX was subsequently maintained on AZA in combination with 5-ASA. A secondary loss of response is reported in nearly $30 \%-50 \%$ receiving maintenance therapy with IFX..$^{22-24}$ The ACT1 and ACT2 extension studies found that nearly $45 \%$ of patients had active disease at week 152 of follow-up. ${ }^{8}$ Similarly, the cumulative rates of maintenance of remission with IFX monotherapy in single center studies from Belgium and Japan were also $68 \%$ at 3 years and $56.1 \%$ at 5 years, respectively. ${ }^{11,23}$

IFX withdrawal after achieving remission has been attempted in patients with Crohn's disease (CD), though not in UC. ${ }^{25,26}$ In a retrospective analysis of patients with CD where IFX was withdrawn, $52 \%$ of patients remained in SCR after a median period of approximately 10 years. ${ }^{27}$ The cumulative relapse-free survivals in our study, though in patients with UC, were $68 \%$, $59 \%, 42 \%$, and $35 \%$ patients at $1,2,4$, and 6 years respectively.

The majority of episodes of relapse were seen in the first 2 years after initiation of 5-ASA and AZA. Most patients experiencing multiple relapses were also seen in the initial 2 years (Table 2, Fig. 2). A systematic review assessing relapse rates after discontinuation of anti-TNF treatment revealed a similar number of relapses at the end of 1 year (21.1\%-39\%), but relapse rates were much higher $(37 \%-55.7 \%)$ at the end of 2 years. ${ }^{28}$ Animal models of colitis have demonstrated that AZA induces production of interleukin 10 (IL-10) by T cells in cultures that are primed for $>6$ days and not in early primed $(<2$ days) cultures despite increasing concentrations of the drug. ${ }^{29}$ AZA thus tilts the balance towards prominence of anti-inflammatory cytokines (decreased serum IL-6, IL-8, IL-17, TNF- $\alpha$ levels and increased IL-10, transforming growth factor $\beta$ ), after a lag period, and the frequency of relapses decreases with time. This could explain greater number of relapses in initial 2 years of follow-up. 5-ASA and AZA combination was well tolerated and only 6 patients, who were intolerant to AZA, had to stop thiopurines.

Patients who experienced relapses during long-term follow up in the current study rarely required a re-induction with IFX and could be managed with repeat course(s) of corticosteroids, suggesting that initial steroid refractoriness is not permanent. Even though a proportion of patients suffered repeated relapses over the period of follow-up (Table 2), majority of these subsequent relapses were also responsive to corticosteroids. Corticosteroids have both immunologic and anti-inflammatory properties, including inhibitory effects on nuclear factor- $\kappa \mathrm{B}$ and activating protein- $-1 .^{30}$ Resistance to corticosteroids is mediated by altered expression of transcription factors and/or cytokines. IL-2 has been shown to promote resistance to corticosteroids by reducing the nuclear translocation of glucocorticoid receptor. T cells from steroid-resistant individuals have been demonstrated to produce more IL-2 than T cells from steroid-sensitive individuals. Blocking IL-2 (via anti-IL-2 [basiliximab] or Janus kinase inhibitors [JAK1 and JAK3]) has been demonstrated to restore steroid sensitivity in vitro. ${ }^{31,32}$ Thiopurines, especially AZA, have anti-proliferative effects that are mediated by direct inhibition of IL-2 and hence could help in re-establishment of response to corticosteroids. ${ }^{33} \mathrm{AZA}$, along with 5-ASA, in the current study therefore may have resulted steroid responsiveness of the relapses occurring during follow up. The colectomy rate in our study was very low. However, colectomy could not be excluded in patients who were lost to follow-up.

The cost of AZA+5-ASA maintenance therapy (including the costs for management of relapses) was approximately INR 53,535 (US\$ 733) per capita per year while maintenance with IFX alone would cost approximately INR 383,906 (US\$ 5,259) per capita per year, which is nearly seven times higher. In a similar cost analysis of contemporary immunomodulatory and biologic strategies in CD, AZA monotherapy was found to be more cost effective than maintenance with IFX alone or IFX+AZA combination and it yielded similar quality-adjusted life years and rates of surgery. ${ }^{34}$

This is the first study where IFX has been withdrawn after inducing remission in patients with UC. This is also the first study to document sustained benefit with use of combination of 5-ASA and AZA in maintaining remission achieved by IFX over a long time (up to 6 years). The limitations of our study 
include the lack of control group, retrospective analysis, high rates of attrition due to loss of follow-up (relapse and/or colectomy cannot be excluded in patients lost to follow-up) and use of clinical parameters to assess efficacy rather than a more precise end point like mucosal healing (endoscopy/biomarkers like fecal calprotectin). However, the present study documents AZA+5-ASA combination as an effective, safe and costbeneficial alternative to maintain remission induced by IFX in acute severe steroid-refractory UC. Larger, prospective studies using the proposed regime are however needed.

To conclude, treatment strategies in resource constrained countries cannot match those followed in developed countries as the health care policies in these countries differ significantly. Induction of remission with IFX and subsequent maintenance with AZA and 5-ASA in patients with acute severe steroid-refractory UC seems to be an effective strategy, sustaining clinical remission over long term. Relapses occur on combination therapy of 5-ASA and AZA but vast majority of these relapses can be managed with repeat course(s) of corticosteroids.

\section{ADDITIONAL INFORMATION}

\section{Funding Source}

The authors received no financial support for the research, authorship, and/or publication of this article.

\section{Conflict of Interest}

Sood A is an editorial board member of the journal but was not involved in the peer reviewer selection, evaluation, or decision process of this article. No other potential conflicts of interest relevant to this article were reported.

\section{Author Contribution}

Conceptualization: Mahajan R, Midha V, Sood A. Data curation: Kedia S, Kaur K, Sahu P, Singh D, Ahuja V. Formal analysis: Mahajan R, Singh A, Kaur K, Bansal N, Dharni K. Investigation: Mahajan R, Singh A, Kedia S, Kaur K, Singh D, Sood A. Methodology: Mahajan R, Singh A, Kedia S, Kaur K, Midha V, Sahu P, Mehta V, Kaushal S, Ahuja V, Sood A. Project administration: Mahajan R, Kedia S, Sood A. Resources: Midha V, Singh D, Sood A. Software: Singh A, Bansal N, Dharni K. Supervision: Mahajan R, Kedia S, Midha V, Ahuja V, Sood A. Visualization: Mahajan R, Singh A, Kedia S. Writing - original draft: Mahajan R, Singh A, Kedia S, Kaur K, Midha V, Sahu P, Mehta V, Ahuja V, Sood A. Writing - review \& editing: Mahajan R, Singh A, Kedia S, Kaur K, Midha V, Sahu P, Mehta V, Bansal N,
Dharni K, Kaushal S, Ahuja V, Sood A. Approval of final manuscript: all authors.

\section{ORCID}

Mahajan R

Singh A

Kedia S

Kaur K

Midha V

Sahu P

Mehta V

Singh D

Bansal N

Dharni K

Kaushal S

Ahuja V

Sood A

https://orcid.org/0000-0001-6726-6151 https://orcid.org/0000-0001-7163-0454 https://orcid.org/0000-0002-5758-0144 https://orcid.org/0000-0001-8530-9493 https://orcid.org/0000-0003-0192-3969 https://orcid.org/0000-0002-9847-0136 https://orcid.org/0000-0002-8867-9526 https://orcid.org/0000-0001-7056-503X https://orcid.org/0000-0002-3601-4565 https://orcid.org/0000-0003-3422-3731 https://orcid.org/0000-0003-2696-410X https://orcid.org/0000-0002-1577-0118 https://orcid.org/0000-0001-6961-6389

\section{REFERENCES}

1. Baumgart DC, Carding SR. Inflammatory bowel disease: cause and immunobiology. Lancet 2007;369:1627-1640.

2. Travis SP, Farrant JM, Ricketts C, et al. Predicting outcome in severe ulcerative colitis. Gut 1996;38:905-910.

3. Turner D, Walsh CM, Steinhart AH, Griffiths AM. Response to corticosteroids in severe ulcerative colitis: a systematic review of the literature and a meta-regression. Clin Gastroenterol Hepatol 2007;5:103-110.

4. Gustavsson A, Halfvarson J, Magnuson A, Sandberg-Gertzén H, Tysk C, Järnerot G. Long-term colectomy rate after intensive intravenous corticosteroid therapy for ulcerative colitis prior to the immunosuppressive treatment era. Am J Gastroenterol 2007;102:2513-2519.

5. Lichtiger S, Present DH, Kornbluth A, et al. Cyclosporine in severe ulcerative colitis refractory to steroid therapy. $\mathrm{N}$ Engl J Med 1994;330:1841-1845.

6. Sood A, Midha V, Sood N, et al. Cyclosporine in the treatment of severe steroid refractory ulcerative colitis: a retrospective analysis of 24 cases. Indian J Gastroenterol 2008;27:232-235.

7. Sood A, Midha V, Sharma S, et al. Infliximab in patients with severe steroid-refractory ulcerative colitis: Indian experience. Indian J Gastroenterol 2014;33:31-34.

8. Reinisch W, Sandborn WJ, Rutgeerts P, et al. Long-term infliximab maintenance therapy for ulcerative colitis: the ACT- 1 and -2 extension studies. Inflamm Bowel Dis 2012;18:201-211.

9. Roda G, Jharap B, Neeraj N, Colombel JF. Loss of response to 
anti-TNFs: definition, epidemiology, and management. Clin Transl Gastroenterol 2016;7:e135.

10. Turner D, Seow CH, Greenberg GR, Griffiths AM, Silverberg MS, Steinhart AH. A systematic prospective comparison of noninvasive disease activity indices in ulcerative colitis. Clin Gastroenterol Hepatol 2009; 7:1081-1088.

11. Ferrante M, Vermeire S, Fidder H, et al. Long-term outcome after infliximab for refractory ulcerative colitis. J Crohns Colitis 2008;2:219-225.

12. Ozaki R, Kobayashi T, Okabayashi S, et al. Histological risk factors to predict clinical relapse in ulcerative colitis with endoscopically normal mucosa. J Crohns Colitis 2018;12:1288-1294.

13. Rubin DT, Ananthakrishnan AN, Siegel CA, Sauer BG, Long MD. ACG clinical guideline: ulcerative colitis in adults. Am J Gastroenterol 2019;114:384-413.

14. Harbord M, Eliakim R, Bettenworth D, et al. Third European evidence-based consensus on diagnosis and management of ulcerative colitis. Part 2: current management. J Crohns Colitis 2017;11:769-784.

15. Puri AS, Desai D, Sood A, Sachdeva S. Infliximab-induced tuberculosis in patients with UC: experience from India-a country with high prevalence of tuberculosis. J Gastroenterol Hepatol 2017;32:1191-1194.

16. Gustavsson A, Järnerot G, Hertervig E, et al. Clinical trial: colectomy after rescue therapy in ulcerative colitis: 3-year followup of the Swedish-Danish controlled infliximab study. Aliment Pharmacol Ther 2010;32:984-989.

17. Lamers CB, Griffioen G, van Hogezand RA, Veenendaal RA. Azathioprine: an update on clinical efficacy and safety in inflammatory bowel disease. Scand J Gastroenterol Suppl 1999; 230:111-115.

18. Nikolaus S, Raedler A, Kühbacker T, Sfikas N, Fölsch UR, Schreiber S. Mechanisms in failure of infliximab for Crohn's disease. Lancet 2000;356:1475-1479.

19. Laharie D, Bourreille A, Branche J, et al. Ciclosporin versus infliximab in patients with severe ulcerative colitis refractory to intravenous steroids: a parallel, open-label randomised controlled trial. Lancet 2012;380:1909-1915.

20. Roda G, Marocchi M, Sartini A, Roda E. Cytokine networks in ulcerative colitis. Ulcers 2011;2011: e391787.

21. Hindryckx P, Jairath V, D’Haens G. Acute severe ulcerative colitis: from pathophysiology to clinical management. Nat Rev Gastroenterol Hepatol 2016;13:654-664.

22. Yokoyama Y, Kamikozuru K, Watanabe K, Nakamura S. Inflammatory bowel disease patients experiencing a loss of response to infliximab regain long-term response after undergoing granulocyte/monocyte apheresis: a case series. Cyto- kine 2018;103:25-28.

23. Yamada S, Yoshino T, Matsuura M, et al. Long-term efficacy of infliximab for refractory ulcerative colitis: results from a single center experience. BMC Gastroenterol 2014;14:80.

24. Nasuno M, Miyakawa M, Tanaka H, Motoya S. Short- and long-term outcomes of infliximab treatment for steroid-refractory ulcerative colitis and related prognostic factors: a single-center retrospective study. Digestion 2017;95:67-71.

25. Louis E, Mary JY, Vernier-Massouille G, et al. Maintenance of remission among patients with Crohn's disease on antimetabolite therapy after infliximab therapy is stopped. Gastroenterology 2012;142:63-70.

26. Kang B, Choi SY, Choi YO, et al. Subtherapeutic infliximab trough levels and complete mucosal healing are associated with sustained clinical remission after infliximab cessation in paediatric-onset Crohn's disease patients treated with combined immunosuppressive therapy. J Crohns Colitis 2018; 12:644-652.

27. Papamichael K, Vande Casteele N, Gils A, et al. Long-term outcome of patients with Crohn's disease who discontinued infliximab therapy upon clinical remission. Clin Gastroenterol Hepatol 2015;13:1103-1110.

28. Gisbert JP, Marín AC, Chaparro M. The risk of relapse after anti-TNF discontinuation in inflammatory bowel disease: systematic review and meta-analysis. Am J Gastroenterol 2016; 111:632-647.

29. Huang G, Xiong J. Effect of azathioprine upon inflammation in rats with ulcerative colitis induced by immune complexcombined TNBS/ethanol. Biomed Res 2017;28:2604-2608.

30. Refojo D, Liberman AC, Holsboer F, Arzt E. Transcription factor-mediated molecular mechanisms involved in the functional cross-talk between cytokines and glucocorticoids. Immunol Cell Biol 2001;79:385-394.

31. Goleva E, Kisich KO, Leung DY. A role for STAT5 in the pathogenesis of IL-2-induced glucocorticoid resistance. J Immunol 2002;169:5934-5940.

32. Bantel H, Domschke W, Schulze-Osthoff K, Kaskas B, Gregor M. Abnormal activation of transcription factor NF-kappaB involved in steroid resistance in chronic inflammatory bowel disease. Am J Gastroenterol 2000;95:1845-1846.

33. Bach JF. The mode of action of immunosuppressive agents. In: Neuberger A, Tatum EL, eds. Frontiers of biology. Amsterdam: North-Holland Publishing Co., 1975:21.

34. Reinink AR, Gregory M, Kymes S, Dassopoulos T. Cost-effectiveness analysis of azathioprine vs. infliximab vs. combination therapy for Crohn's disease. Gastroenterology 2011;140(5 Suppl 1): S-175-S-176. 